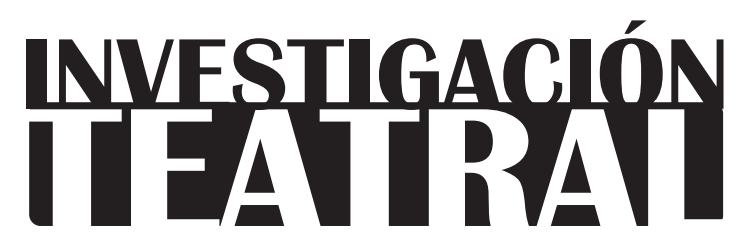

Revista de artes escénicas y performatividad

Vol. 11, Núm. 18

octubre 2020-marzo 2021

Segunda época

ISSN impreso: 1665-8728

ISSN electrónico: 2594-0953

Universidad Veracruzana

Reseña de puesta en escena:

Dos experiencias escénicas argentinas en tiempo de pandemia

\author{
María Natacha Koss*
}

\footnotetext{
* Instituto de Artes del Espectáculo, Facultad de Filosofía y Letras, Universidad de Buenos Aires, Argentina.

e-mail:natachakoss@yahoo.com.ar
}

Recibido: 30 de junio de 2020

Aceptado: 16 de julio de 2020

Doi: https://doi.org/10.25009/it.v11i18.2645 


\section{Dos experiencias escénicas argentinas en tiempo de pandemia}

\section{Todo que oír}

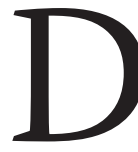

esde 1996, existe en la ciudad de Tandil, provincia de Buenos Aires (Argentina), el Club de Teatro, un espacio de creación, formación y difusión de las artes escénicas. Fundado y dirigido desde sus inicios por Marcela Juárez y Alejandra Casanova, el proyecto ha ido creciendo y consolidándose en el tiempo como un polo cultural. Marcela Juárez, quien también es profesora de la Facultad de Arte de la Universidad Nacional del Centro, ha creado, junto a su colega Guillermo Dillon, de la misma universidad, un original teatro sonoro, primo hermano del radioteatro y creación forzosa del aislamiento por la pandemia. Juárez ya había experimentado el trabajo con restricciones sensoriales con el ciclo Nada que ver, una experiencia de teatro oscuro que, estrenada en 2009, ha tenido diferentes entregas y reediciones a lo largo de la última década.

Estamos ahora en presencia de un trabajo tecnovivial que continúa y profundiza ese teatro ciego original. Se trata del ciclo Todo que oír, fascinante realización a la que se accede por YouTube y que hay que escuchar con auriculares y los ojos bien cerrados.

Nos cuenta Dillon que, en el intento de

[...] continuar con el trabajo como docentes e investigadores de teatro en medio del aislamiento social obligatorio, nuestro espacio de teatristas quedó relegado. Reapareció, así, una vieja propuesta de combinar las investigaciones sobre teatro oscuro de Marcela Juárez, junto a las manipulaciones tecno-sonoras que produzco y que no habíamos encontrado manera de enlazarlas en un espacio convivial teatral. La absti- 
nencia teatral forzada inauguró un espacio grupal virtual que - pantallas medianterecuperó saberes y formas de crear propios. Hoy Todo que oír (parafraseando a Nada que ver) toma la forma de episodios de relatos espacializados grabados que convocan a un auditor con auriculares y ojos cerrados, evocando levemente el ritual que tantos espectadores disfrutaron en las 3 ediciones de la obra de teatro Nada que $\operatorname{ver}$ (entrevista). ${ }^{1}$

La experiencia de un teatro oscuro modifica profundamente no sólo la relación del espectáculo con los espectadores, sino también la de los espectadores entre sí. La comunidad, la pertenencia a un público, que promueve la identidad colectiva adelgazando la individual, se ve subvertida ante la ausencia del sentido de la vista. Afirma Juárez que

[...] si bien el teatro sensorial en oscuridad postula por un lado un actor coral/colectivo y un espectador individual (ya no un cuerpo público), en este caso la tecnología ofrece una nueva relación: un 'uno a uno'. Se trata de una teatralidad 'al oído' sucedida en el ámbito doméstico y con un espectador singular, aislado en un juego propio de escucha (entrevista).

Asimismo, el sonido aparece como un objeto manipulable en su triple condición de ícono, índice y símbolo. "Además de todas las consideraciones psicoacústicas del arte sonoro -sostiene Dillon- emerge con la tecnología una dimensión teatral impensada; [los objetos] pueden ser manipulados, deslocalizados, fundidos y transformados con un gran potencial poético".

Como afirmábamos más arriba, si bien puede establecerse una línea genealógica con el radioteatro, esta propuesta no busca emular o suplir la experiencia teatral ausente, ni transformarse solamente en una experiencia narrativa que construya con el sonido lo que se sustrae del campo visual. Por el contrario, asistimos a una "inmersión sensorial", una experiencia individual intermediada por la virtualidad. Hay, por supuesto, una construcción de imágenes ilusorias a partir de lo sonoro, pero que se suman a sonidos grabados en distintos contextos que se funden creando paisajes acústicos.

Así como puede vincularse con el radioteatro, esta experiencia también está hermanada con los contenidos ASMR (Autonomous Sensory Meridian Response), es decir, por las experiencias placenteras o de euforia de bajo grado ${ }^{2}$ generada por estímulos auditivos. La

1 Todas las citas, a menos que se indique lo contrario, corresponde a material y declaraciones facilitadas por los artistas a la autora.

2 Según Beltrán Bretones, "la ASMR ha adquirido diferentes denominaciones desde el momento de su apari- 
propuesta apela también, programáticamente, a suspender la mirada. El aislamiento al que nos obliga la pandemia ha otorgado a las pantallas una supremacía acelerada en nuestro vínculo con el mundo. Todo que oír convoca entonces, según Juárez, "a descansar un momento de las ráfagas de imágenes visuales virtuales que recibimos diariamente y que han capturado nuestro espacio sensorial cotidiano".

\section{APOCALIPSYNC_}

Otra increíble propuesta que también se puede ver online es APOCALIPSYNC_que, si bien nace como un proyecto de espectáculo teatral, encontró la manera de capitalizar las limitaciones de la pandemia. Dicen sus realizadores que:

[...] A partir de la situación de pandemia global y a la espera de poder volver al formato escénico, decidimos reinventar el concepto para llevarlo a un formato online. Durante el confinamiento creamos este show en el living de casa, con una luz circular y un teléfono celular. La versión audiovisual de APOCALIPSYNC_ es un show en sí mismo, pero también es una pequeña muestra de lo que será la versión escénica el día que podamos volver a ocupar las salas teatrales (Rosso e Israilevich). ${ }^{3}$

Con un iphone 11 y una luz circular para teléfonos, Luciano Rosso lleva su poética del playback a una nueva dimensión. Ya habíamos visto algo de su trabajo en los bonus tracks, los bis, que Rosso ofrecía en el final de Un poyo rojo, obra que protagonizaba junto a Nicolás Poggi con dirección de Hermes Gaido. Esta pieza, que se encontraba en el campo liminal entre la danza y el deporte, se mantuvo en cartel entre 2009 y 2016. Pero desde 2010 en adelante, Rosso brindaba al público -luego de los aplausos finales y con luz de sala- un

ción en el año 2007. Las primeras aproximaciones definen la ASMR como "una sensación extraña e indescriptible que te hace sentir bien, un hormigueo que recorre todo el cuerpo que se desplaza por la columna y llega hasta las extremidades" (Novella, 2012). Posteriormente, fue recibiendo diferentes nombres como son: "Attention-Induced Head Orgasm" o "Attention Induced Observant Euphoria" (Richard, 2015). En la actualidad, esa sensación de bienestar se denomina euforia de bajo grado. Consultar el trabajo de final de grado en Psicología de Beltrán Bretones, María Teresa. Estudio de la influencia de la respuesta sensorial meridiana autónoma (ASMR) en la concentración y motivación frente al estudio. Universitat Jaume I, Castellón de la Plana, España., 2016. Disponible en hdl.handle.net/10234/164545

3 N. del Ed.: La cita fue tomada de la caja de descripción del video, el cual puede verse en www.youtube. com/watch?v=0yzqvDAC7vo 
número extra. Sentado en un banco de madera, apelando a la gestualidad del rostro y del cuerpo, exploraba la técnica del playback con canciones como "Se dice de mí", "El pollito pío" o "Eblouie par la nuit". Siguió experimentando con diversas melodías en su canal de YouTube y, hoy, con una técnica muy depurada, aborda esta propuesta en donde suma los recursos del videoarte.

Con un alto grado de comicidad, divide a su trabajo en diversas secciones que se van intercalando, en las que ya no realiza solamente playbacks de canciones. Ahora también le pone cuerpo a las voces de diversos actores españoles dedicados al doblaje (extraídas del documental Voces en imágenes. Un homenaje a los actores de doblaje del cine español, de Alfonso S. Suárez), a un robot femenino y a todo un universo de objetos inanimados. Con gran virtuosismo técnico, Rosso logra danzar con el gesto, danzar con el rostro.

Creo que el cuerpo de un intérprete es su herramienta, su instrumento. El cuerpo TODO es una unidad integral capaz de transmitir cosas inimaginables [...] la mayoría de la gente conoce mi rostro y mis gestos pero no conoce mucho más de mi trabajo, o tal vez han visto algo por internet, pero hace 15 años que me dedico a la actuación, la música y la danza. ${ }^{6}$

Poner el cuerpo a voces y sonidos no significa, necesariamente, "explicar" esas voces o sonidos. Muchas veces el trabajo es de contraste, de oposición, generando un efecto cómico por la construcción del personaje. La poética del playback, tan poco estudiada hasta el día de hoy, merece un abordaje más sistemático y exhaustivo en el futuro, aunque no sea más que para encontrar herramientas que nos permitan pensar espectáculos como este.

Si bien, en los dos casos que abordamos aquí, el convivio está forzosamente ausente, el acontecimiento teatral permanece por evocación. Pero ya no es sólo el recuerdo o la añoranza que generan los espectáculos grabados, sino más bien unas experiencias tecnoviviales liminales que, creemos, han llegado para quedarse, multiplicando, así, los recursos del teatro y haciendo estallar los límites -ya estallados- entre las artes.

4 Ver www.youtube.com/watch?v=-CbemqttozE

5 Ver www.youtube.com/watch?v=vZMMC_quqau

6 Entrevista realizada por Daniel Santos para el diario La voz del interior, 6 de julio de 2015 


\section{Ficha técnica}

\section{Todo que oír}

Realizados durante el período de aislamiento social obligatorio, en la ciudad de Tandil.

Se accede por www.youtube.com/watch?v=yamnzYvzImk

Episodio 1

Fecha de estreno: 28 de abril de 2020.

Dramaturgia Sonora: Marcela Juárez-Guillermo Dillon.

Voz: Julieta Landivar.

Sobre un relato de: E. Anderson Imbert.

Música presentación: Mariano Delaude.

Episodio 2

Fecha de estreno: 19 de junio de 2020.

Dramaturgia Sonora: Marcela Juárez-Guillermo Dillon.

Sobre un relato de: Lucila Baudrix.

Música presentación: Mariano Delaude.

APOCALIPSYNC_

Realizada entre mayo y junio de 2020 en Buenos Aires, durante el período de aislamiento social obligatorio.

Fecha de estreno: 21 de junio de 2020.

Se accede por youtu.be/OYZqvDAC7vo

Idea y Realización: Luciano Rosso \& Miguel Israilevich.

Producción: Jonathan Zak \& Maxime Seugé.

\section{Fuentes consultadas}

Dillon, Guillermo. Entrevista personal. 30 de junio de 2020

Juárez, Marcela. Entrevista personal. 30 de junio de 2020.

Rosso, Luciano. "Luciano Rosso, el genio del playback antes del dubsmash: 'El cuerpo puede transmitir cosas inimaginables"'. La voz, 6 de julio de 2015, vos.lavoz.com.ar/ mira/luciano-rosso-el-genio-del-playback-antes-del-dubsmash-el-cuerpo-puedetransmitir-cosas, consultado el 31 de julio de 2020. 